\title{
PARA UMA (RE)MITIFICAÇÃO DOS NIBELUNGEN NO PERÍODO ENTRE GUERRAS MUNDIAIS
}

\author{
Daniele Gallindo G. Silva ${ }^{1}$ \\ Expresso meus agradecimentos ao colega Dr. Vinícius Dreger que auxiliou nessa em- \\ preitada ao discutir algumas passagens e sugerir leituras.
}

Resumo: À luz do conceito de mito político, esse artigo propõe discutir a relação estabelecidade entre Das Nibelungenlied e suas releituras nos períodos de Guerras em território alemão. Para tanto, lançaremos mão da análise comparada de imagens, discursos políticos, poemas e narrativas com a finalidade de compreender como a temática em questão foi remitificada nesses anos.

Palavras-chave: Das Nibelungenlied, mito político, Guerras Mundiais, Nacional-Socialismo

Abstract: Considering the concept of political myth, this paper aims to discuss the relationship established between Das Nibelungenlied and its readings in the wars' periods in Germany. Thus, it intends a comparative analysis of images, political speeches, poems and narratives in order to understand how the issue in question was remythified in those years.

Keywords: Das Nibelungenlied, political myth, World Wars, National Socialism

\footnotetext{
1 Professora Adjunta de Língua e Literaturas de Língua Alemã da UFPel. E-mail: danigallindo@yahoo.de
} 
O grande imperador ou o rei justo que retornará, o herói invencível e valoroso que incorpora a pátria, a cidade na qual grandes revoluções ocorreram, o burgo dentro do qual uma grande obra foi traduzida. Não há dúvidas em afirmar que a História da Alemanha é povoada de mitos desde seus primórdios até os dias atuais.

Durante o século XIX, foi a busca ideológica por uma identidade nacional que levou os intelectuais românticos a lançar mão de personagens históricas, de lendas medievais e de histórias orais afim de construir as bases para a futura unificação sob Bismarck em 1871. Zygmunt Baumann afirma, neste sentido, que "para se tornar nacional, a cultura tinha primeiro de negar que fosse um projeto: precisava disfarçar-se de natureza" (Bauman, 2012, p. 51). Neste disfarce da cultura como natureza, os mitos servem como ratificação e legitimação de um passado em comum e, por consequência, de uma pretensa unidade enquanto nação. Dentro dessa lógica romântica de incitar a formação de uma nação calcada não na guerra - como no caso francês -, mas sim em uma base cultural, Novalis (Georg Philipp Friedrich Freiherr von Hardenberg) afirma que essa seria a vantagem futura dos alemães sobre as outras nações (cf. Novalis, apud Safranski, 2009, p. 176): fundamenta-se, assim, a noção de Kulturnation (nação cultural). ${ }^{2}$ Conceito este que não foge a programática proposta por Friedrich Schlegel, no 116. Athenäum Fragement, da universalidade da poesia romântica. Destarte, como afirmado por Stefan Laube (2005, p. 1),

Die Nation ist eine Tatsache des Denkens, der Sprache und des Willens. Erst wenn man sie sich bewusst macht, sie in Worte fasst, wünscht oder fordert, tritt sie ins Leben. Die Nation war keine kollektive Substanz aus Urtiefen der Volksseele, wie noch die Romantiker unter Berufung auf Herder glaubten, vielmehr wurde sie von Wenigen konstruiert und erfunden, von Intellektuellen, Dichtern, Philosophen, Historikern, Philologen und Künstlern. ${ }^{3}$

Neste contexto, vislumbramos as primeiras utilizações de personagens históricas e temas medievais com algum caráter político. A Idade Média se torna, portanto, uma "superfície de projeção positiva"4 (Kaiser, 2010, p. 13).

$\mathrm{Na}$ definição clássica de mito, esse relaciona-se ao conceito de "história verdadeira" e "sacralidade", havendo uma ligação com um tempo passado, como asseverado por Mircea Eliade (1998). Para muito além dessa noção redutora, o mito possui uma dimensão simbólica, que auxilia em determinadas construções sociais. Essa dimensão do mito torna-se mais nítida quando a discussão se centra na questão do mito político.

De acordo com Münkler, os mitos políticos "sind die narrative Grundlage der symbolischen Ordnung eines Gemeinwesens, die insbesondere dann in Anspruch genommen werden muss, wenn sich Symbolik nicht mehr erschließen oder wenn es gilt,

\footnotetext{
2 Maiores discussões acerca do conceito de Kulturnation cf. Schulze, 2004, p. 126-150.

3 "A nação é um fato do pensamento, da língua e da vontade. Só quando se concientiza, a exprime em palavras, se deseja ou fomenta, ela toma vida. A nação não é qualquer substância coletiva das profundezas da alma do povo, assim como os românticos acreditavam, citando Herder, foi muito mais projetada por alguns poucos e inventada por intelectuais, poetas, filósofos, historiadores, filólogos e artistas."

4 "positive Projektionsfläche".
} 
sie zu verändern"5 (Münkler, 2011, p. 15-16). Através de mitos políticos ocorre, então, uma resignificação do material originário que acaba por criar uma nova ordem simbólica que se torna reconhecida como uma matéria coletiva. Neste sentido, Luis Felipe Miguel conclui que

Enquanto elemento de um discurso que se deseja eficaz, o mito político possui uma dupla origem. Ele é fruto, menos ou mais refletido, de uma estratégia política. O emissor do discurso o escolhe confiando em sua utilidade. Mas não é correto reduzi-lo à "demagogia", e não apenas porque não é necessário (embora seja possível) que seu veiculador o vivencie como "mistificação". O mito é também um produto coletivo. (Miguel, 1998, s/p)

Tendo como recorte temático os Nibelungen e temporal o século XX, mais precisamente do ano de 1909 até 1945, propomos verificar como as personagens Siegfried e Hagen von Tronje de Das Nibelungenlied ${ }^{6}$ e alguns conceitos desta saga heróica foram relidos e reinterpretados em território alemão criando, assim, todo um imaginário político. ${ }^{7}$

\section{CASO 1: DIE NIBELUNGENTREUE ${ }^{8}$}

Em meio a crise da Bósnia ou Crise da anexação (1908-1909), o Chanceler do Império Alemão (Reichskanzler) Bernhard von Bülow declara abertamente em doze de novembro de 1908 apoio ao Império Austro-Húngaro ao afirmar que estariam na retaguarda deste, ainda que não tomasse a sua frente. ${ }^{9}$ Entretanto, a primeira referência ao tema nibelungos encontra-se no discurso de Bülow de vinte e nove de março do ano de 1909, ao reiterar o apoio irrestrito ao Império Austro-Húngaro.

Meine Herren, ich habe irgendwo ein höhnisches Wort gelesen über unsere Vasallenschaft gegenüber Österreich-Ungarn. Das Wort ist einfältig! Es gibt hier keinen Streit um den Vortritt wie zwischen den beiden Königinnen im Nibelungenlied; aber die Nibelungentreue wollen wir aus unserem Verhältnis zu Österreich-Ungarn nicht ausschalten, die wollen wir gegenseitig wahren. ${ }^{10}$ (Bülow, apud Münkler, 2011, p. 81)

\footnotetext{
5 "são a base narrativa da ordem simbólica de essência coletiva, que deve ser especialmente levada em consideração, quando o simbolismo não mais se revela ou quando é necessário alterá-los”

6 Tradução para o português A Canção dos Nibelungos. Trata-se de uma Heldenepik (saga heróica) copilada no século XIII em Mittelhochdeutsch (médio-alto-alemão). Estruturalmente a narrativa se apresenta em estrofes e narra fatos "nacionais", em sua maioria, da época da migração dos povos. Não podemos deixar de ressalta, ainda, o fato dessa narrativa integrar um conjunto de textos transmitidos oralmente, que foram compilados em épocas posteriores; em geral, de caráter anônimos (Brandt, 1999, p. 204). No artigo aqui proposto partimos da seguinte edição: Das Nibelungenlied. Nach der Ausgabe von Karl Bartsch. Wiesbaden: Albert, 1996. (Deutsche Klassiker des Mittelalters).

7 Ressaltamos o papel importante da política pedagógica nacional-socialista para reforçar a remitificação dos Nibelungos. Contudo, esse recorte configuraria um outro trabalho.

8 A lealdade dos Nibelungos

9 "Wir haben nicht den Beruf, uns vor Österreich-Ungarn zu stellen, aber wir müssen hinter Österreich-Ungarn stehen" (Nós não temos a vocação de nos colocarmos a frente da Áustria-Hungria, mas nós temos que nos colocar atrás da Áustria-Hungria.", Bülow, apud Münkler, 2011, p. 82).

10 "Senhores, eu li em algum lugar uma palavra sarcástica sobre a nossa vassalagem em relação à Áustria-Hungria. A palavra é simplória! Não há, aqui, qualquer conflito à precedência como entre os dois reinos na Canção dos Nibelungos,
} 
Em seu discurso, o chanceler ressalta o conflito instaurado entre burgúndios/nibelungos e hunos na por ele referida Nibelungenlied. Ressaltando, entretanto, que a lealdade é um das prerrogativas do relacionamente entre os dois impérios. A Nibelungentreue refere-se, no caso da saga heróica, à relação entre Hagen e seu senhor (Gunther) e senhora (Brünhild) e porque não afirmar que se refere também à lealdade de Kriemhild para com seu marido em querer a vingança pela sua morte de qualquer forma. A passagem retira da 36. Âventiure (36 Aventura) do texto em médio-alto-alemão reforça a ideia da lealdade dos nibelungos, quando os irmãos de Kriemhild, Gernôt e Gîselher, preferem a morte a entregar Hagen - o nobre e leal cavaleiro de sua corte que assinara Siegfried em nome da honra de seus senhores - à dama.

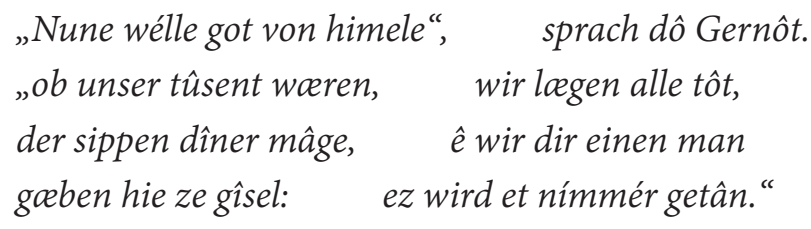

(Das Nibelungenlied, Str. 2105)

Isso impediria Deus no Céu, disse então Gernôt

Se fossemos milhares, todos estaríamos mortos,

A tua estirpe, do que a ti um homem

Daríamos aqui como refém: isso nunca faríamos.

(...) sprach dô Gîselher.

(...)

wande ich deheinen mînen friunt an den triuwen nie verlie.

(Das Nibelungenlied, Str. 2106)

(...) disse então Gîselher (...)

Jamais quebrei a lealdade para com meus amigos.

Deslocada de seu contexto medieval acima exemplificado, a lealdade (triuwe), ${ }^{11}$ a qual se liga intimamente à relação de vassalagem rei/rainha (Gunther/Brünhild) e cavaleiro (Hagen), assume, na fala de Bülow, o valor de uma aliança política entre dois impérios com a finalidade última de salvaguardar suas soberanias.

Alguns anos após o discurso de Bülow, em 1914, o jurista Franz von Liszt retoma em sua fala de dezoito de novembro o discurso do chanceler acerca da Nibelungentreue reafirmando as ideias construídas anteriormente. De acordo com Liszt, "Das Nibelungenlied foi descrita com toda a razão como o Cântico da coragem e da lealdade heróicas alemães"12 (Liszt, apud Heinzle, 2013, p. 310311). A lealdade sai do nível meramente textual e é interpretada pelo jurista como uma qualidade

mas a lealdade dos nibelungos não queremos eliminar do nosso relacionamento com a Áustria-Hungria, aquela queremos proteger reciprocamente."

${ }^{11}$ Sobre o conceito de triuwe em médio-alto-alemão, Otfrid Ehrismann afirma que essa se define tanto em referência ao caráter individual da pessoa, quanto ao caráter coletivo de compromisso e obrigação (Ehrismann, 1995, p. 213).

12 "Das Nibelungenlied ist mit Fug und Recht als das Hohelied von deutschem Heldenmut und deutscher Heldentreue bezeichnet worden". 
inerente ao povo alemão: "dieses innerste Wesen unseres deutschen Volkes ist heute genau dasselbe wie etwa im Jahre 1200, wie in den vergangenen Jahrhunderten, von denen der Sänger des Nibelungenliedes uns erzählt"13 (Liszt, apud Heinzle, 2013, p. 316). Há aqui, portanto, a naturalização, generalização e incorporação de um valor representado em um texto literário medieval que tem sua própria lógica narrativa: a lealdade nibelunga sai do campo literário e entra para o campo social.

Também Thea von Harbou - roteirista do clássico do cinema mudo alemão Die Nibelungen (1924) ${ }^{14}$ - assevera, a priori, ser a Nibelungenlied o "Cântico da lealdade incondicional", ${ }^{15}$ mas ao mesmo tempo afirma que esta "não seria o Cântico da lealdade, mas o sermão mais comovente da expiação de toda culpa"16 (Harbou, apud Heinzle, 2013, p. 58-59).

Assim sendo, podemos concluir que a Nibelungentreue foi (re)criada dentro do discurso político para desenvolver, no campo de batalha, uma virtude militar primordial das tropas (cf. Miklautsch, 1994, p. 374); a de lealdade, acima de tudo, perante à pátria.

\section{CASO 2: DIE DOLCHSTOßLEGENDE ${ }^{17}$}

A lealdade não é a única temática relevante para se compreender a construção do mito político em torno dos nibelungos, mas também e sobretudo questões como "infidelidade, traição e assassinato. Também isso deve ser politicamente significativo no contexto da Primeira Guerra Mundial"18 (Heinzle, 2013, p. 59). A declaração da República (Weimarer Republik) em nove de novembro de 1918 por Philipp Scheidemann, o Armistício de Compiègne assinado em onze de novembro do mesmo ano, que teve como representante alemão Matthias Erzberger, bem como a Novemberrevolution (Revolução de Novembro) oferecem, a priori, o ambiente ideal para uma nova releitura da temática nibelunga: Die Dolchstoßlegende (a Lenda da punhalada pelas costas).

De acordo com Bernd Seiler, a primeira fonte reconhecida no que diz respeito ao emprego da palavra Dolch(stoß) foi a publicação da edição número 1675 de dezessete de dezembro de 1918 do Neue Zürcher Zeitung, a qual termina com as seguintes palavras: ${ }^{19}$ "Was die deutsche Armee betrifft, so kann die allgemeine Ansicht in das Wort zusammengefaßt werden: Sie wurde von der Zivillbevölkerung von hinter erdolcht" ${ }^{20}$ (apud Seiler, 1966, p. 5). Nessa passagem fica expressa uma justificativa ideológica para a derrota na Primeira Guerra, que culpabiliza o próprio povo. Na lógica por ela expressa, o inimigo não é encarado

\footnotetext{
13 "Esta essência mais íntima do nosso povo alemão é hoje exatamente a mesma que no ano de 1200, como nos séculos passados, da qual o trovador da Canção dos Nibelungos nos narra."

${ }^{14}$ Embora, o filme de Fritz Lang e Thea von Harbou também seja uma recepção da Nibelungenlied e insira-se no período aqui selecionado, não analisaremos esta obra por sua extensão e características próprias. A mesma merece um trabalho dedicado somente a sua interpretação.

15 "Hohelied von bedingungsloser Treue"

16 "nicht das Hohelied der Treue, sondern die erschütterndste Predigt von der Sühne jeder Schuld”.

17 A lenda da punhalada nas costas.

18 "Treulosigkeit, Verrat und Mord. Auch dies sollte im Zusammenhang mit dem Ersten Weltkrieg politisch bedeutsam werden."

19 Seiler assevera que se trataria de uma matéria com o General Frederick Maurice. Todavia, o general afirma que nunca utilizou o vocábulo punhalada (Seiler, 1966, p. 5).

20 "No que se refere ao exército alemão, assim pode ser resumida, em palavra, a visão geral: este foi esfaqueado pelas costas pela população civil"
} 
como superior ou vitorioso, mas os alemães se deixaram apunhalar sem que percebessem em seu próprio campo pelo seu próprio povo.

Nos anos que se seguem, releituras sucessivas da punhalada pelas costas são construídas iconograficamente em jornais, revistas e panfletos de propaganda política. Cada mídia representou os apulhadores de acordo com o discurso incorporado por seus organizadores.

Em um postal austríaco do ano de 1919 (figura 1), visualizamos um soldado na trincheira sendo apunhalado pelas costas por um judeu, o que aponta para um discurso antisemita. Esse figura representando um judeu parece, todavia, uma alegoria da República - lembremos, ainda, da imagem de Eugène Delacroix da Liberdade guiando o povo -, de prováveis republicanos judeus traidores que inviabilizaram a vitória na Guerra.

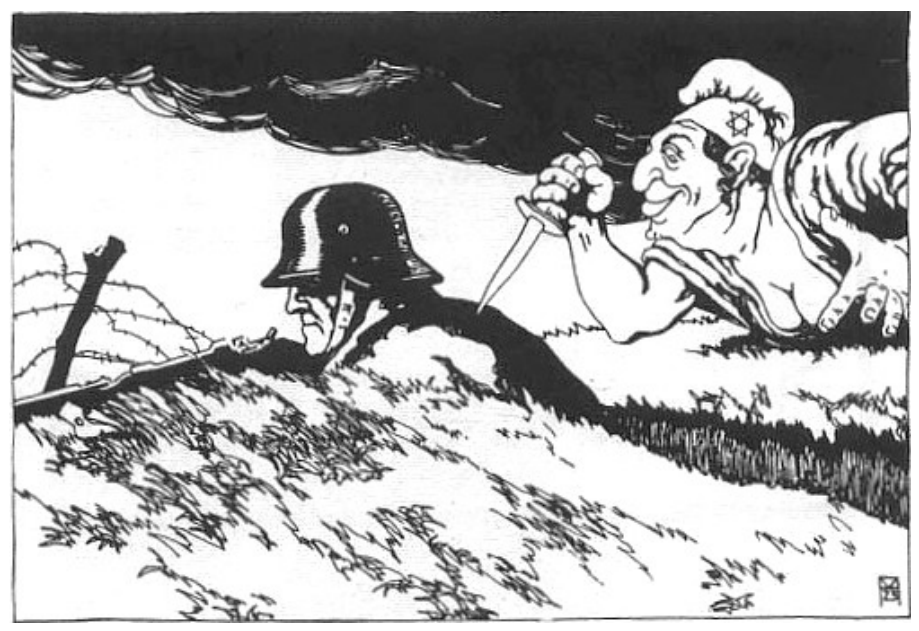

Figura 1

Fonte: Domínio público. Disponível em: http://www.history.ucsb.edu/faculty/marcuse/projects/reception/recimages/193DolchstossJewGerman.jpg

Em 1920, embebido nesse espírito de traição, o Feldmarschall (marechal de campo) Paul von Hindenburg, comenta a situação de guerra e relaciona diretamente a punhalada com a cena da Das Nibelungenlied em que Hagen fere mortalmente Siegfried, reproduzida a seguir.

Dâ der herre Sîfrit $\quad$ ob dem brunnen tranc,

er schôz in durch das kriuze, dazvon der wunden spranc

daz bluot im von dem herzen vaste an Hagenen wât

sô grôze missewende ein helt nimmer mêr begât.

(Das Nibelungenlied, Str. 981)

Quando Siegfried bebia da fonte.

Ele atingiu-o através da cruz, de forma a jorrar do ferimento

Sangue de seu coração, manchando a veste de Hagen

Nenhum guerreiro nunca cometeu tão grande injustiça.

No discurso de Hindenburg, Hagen é qualificado como cruel e Siegfried incorpora o herói da pátria, ou seja, os soldados traídos. Poderíamos, ainda, analisar a menção à personagem 
Siegfried como uma metáfora para toda a Alemanha. O marechal, ainda, retoma a imagem de beber da fonte, sendo que em seu discurso esta liga-se a uma tentativa de retomar as forças perdidas em batalha. Contudo, de nada adianta buscar forças na pátria, pois nela não há qualquer apoio. Hindenburg afirma: "Wie Siegfried unter dem hinterlistigen Speerwurf des grimmen Hagen, so stürzte unsere ermattete Front; vergebens hatte sie versucht, aus dem versiegenden Quell der heimatlichen Kraft neues Leben zu trinken." ${ }^{21}$ (Hindenburg, 2013, p. 314).

Todavia, a remitificação, aqui no sentido de uma resimbolização do mito, da lenda da punhalada pelas costas recebeu críticas que se opunham à aura anti-republicana que se formou gradativamente em torno do tema. Segundo Adolf Köster - político alemão pertencente ao SPD (partido socialdemocrata alemão) e ministro do exterior (Außenminister) em $1920 \mathrm{e}$ ministro para assuntos internos (Innenminister) de 1921 a 1922 -, esta seria "eine der bösartigsten und zugleich dümmsten Legenden. die gegen die Republik mobilisiert werden sind"22 (Köster, apud Seiler 1966, p. 10).

No âmbito de toda essa controvérsia, não se pode negar que a tensão crescia entre apropriação e remitificação política da temática da punhalada traiçoeira pelas costas e a negação da relevância dessa para se compreender o final da Primeira Guerra, mais especificamente a derrota em 1918 (Seiler, 1966, p. 13), e os arranjos decorrentes desta. Através de panfletos, jornais e revistas, o imaginário da população era alimentado com diferentes releituras da cena primária da punhalada pelas costas.

$\mathrm{Na}$ imagem que se segue (figura 2), publicada em três de março de 1924, estão representados os dois grandes apunhaladores da pátria dentro do discurso contemporâneo: Scheidemann, proclamador da república, e Erzberger, representante alemão na assinatura do armistício. Novamente há a imagem de soldados entrincheirados que serão apunhalados pelas costas pelos 'civis'. A legenda convoca a nação a refletir sobre o assunto: Deutsche, denkt daran!

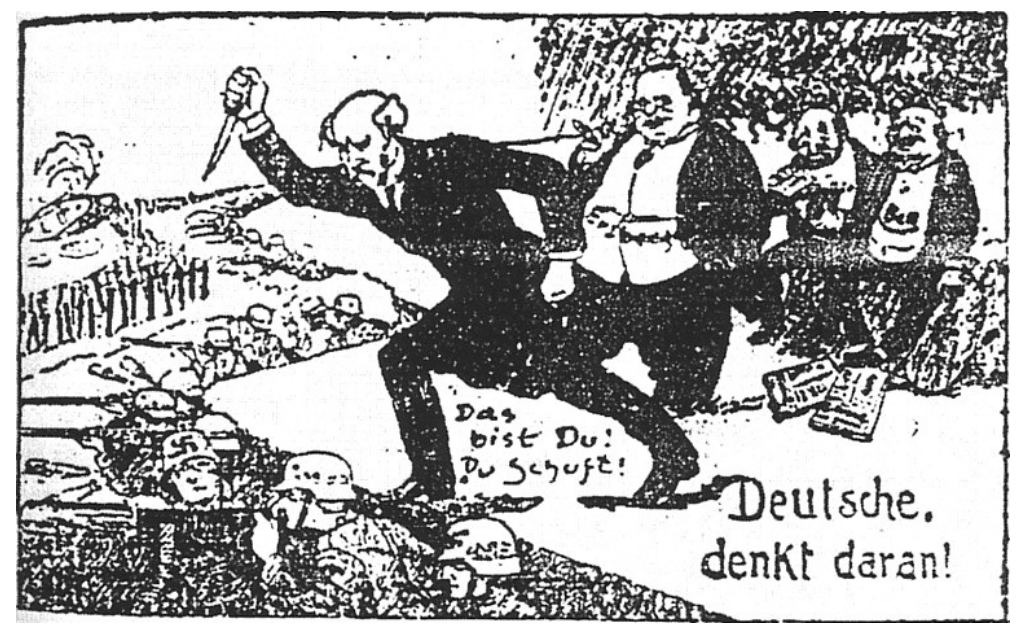

\section{Figura 2}

Fonte: Domínio público. Disponível em http://www.history.ucsb.edu/faculty/marcuse/projects/reception/recimages/245DolchstossScheidemann.jpg

\footnotetext{
${ }_{21}$ "Como Siegfried sob a pérfida lança do terrível Hagen, assim caiu nossa fronte extenuada, em vão ela tentou beber nova vida da fonte seca da força pátria"

22 "uma das mais cruéis e, ao mesmo tempo, estúpidas lendas que se mobilizou contra a República"
} 
Em dezembro de 1924, há na Alemanha eleições para o parlamento, na qual Paul von Hindenburg assume a presidência e partidos nacionalistas como o DNVP (Partido Popular Nacional Alemão) e o NSDAP (Partido Nacional Socialista dos Trabalhadores Alemães) ganham força no cenário político. O discurso da punhalada é tomado por nacionalistas para justificar suas restrições para com a República, como podemos verificar no cartaz a seguir de 1924 (figura 3).

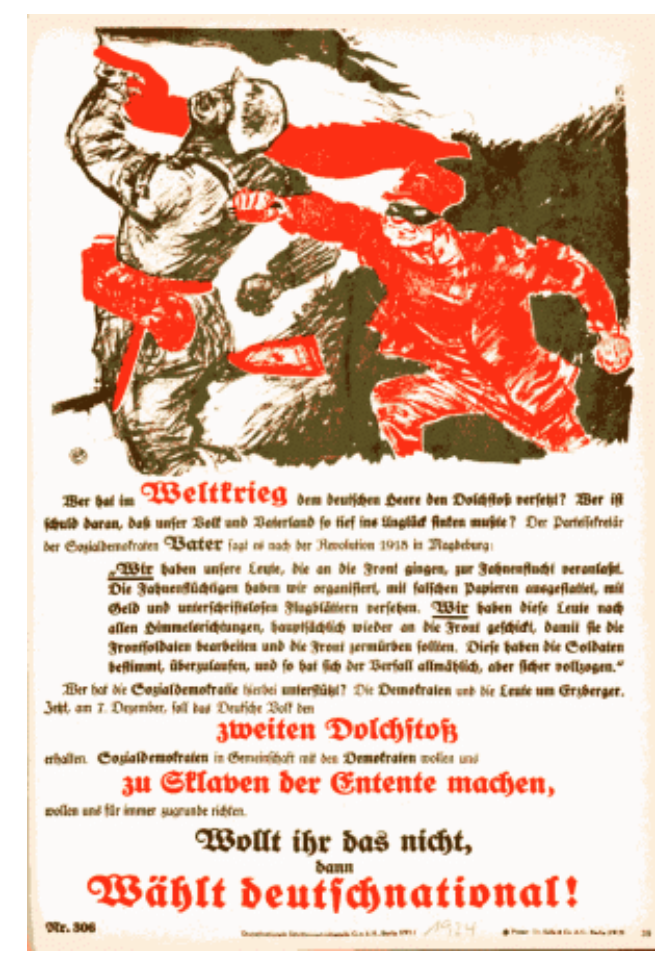

Figura 3

Fonte: Domínio público. Disponível em http://www.muenster.de/stadt/strassennamen/hindenburg_generalfeldmarschall.html

Ainda que o autor não seja mencionado, trata-se de uma propaganda política panfletária e pode ser atribuída ao DNVP, principalmente se observamos a estrutura em imperativo ao final: "Wählt deutschnational!" (Vote nacional-alemão!) Ainda destacadas em vermelho encontramos expressões-chave para compreender as intenções dessa propaganda: "Weltkrieg” (Guerra Mundial), "zweiten Dolchstoß" (segunda punhalada), "zu Sklaven der Entente machen" (fazer-[nos] de escravos da entente). Associadas à imagem, que mostra um soldado, provavelmente alemão, sendo apunhalado pelas costas por um assassino trajando vermelho, os termos selecionados situam o (e)leitor e apelam àqueles que não desejam uma nova traição à pátria. A escolha da cor vermelha éuma menção no campo visual ao SPD (Partido Social-Democrata da Alemanha) - mencionados no texto algumas vezes -, partido líder até o momento, ao qual pertencia Philipp Scheidemann e Paul von Hindenburg, candidato à eleição. Discurso este que se repete tanto em imagem quanto em texto do cartaz a seguir (figura 4): “Deutsches Volk, denk' daran!” Novamente o povo é conclamado a pensar nos acontecimentos do passado, sendo que neste a menção à punhalada (Der Dolchstoß) é duplamente visual: há a fusão entre imagem e texto. 


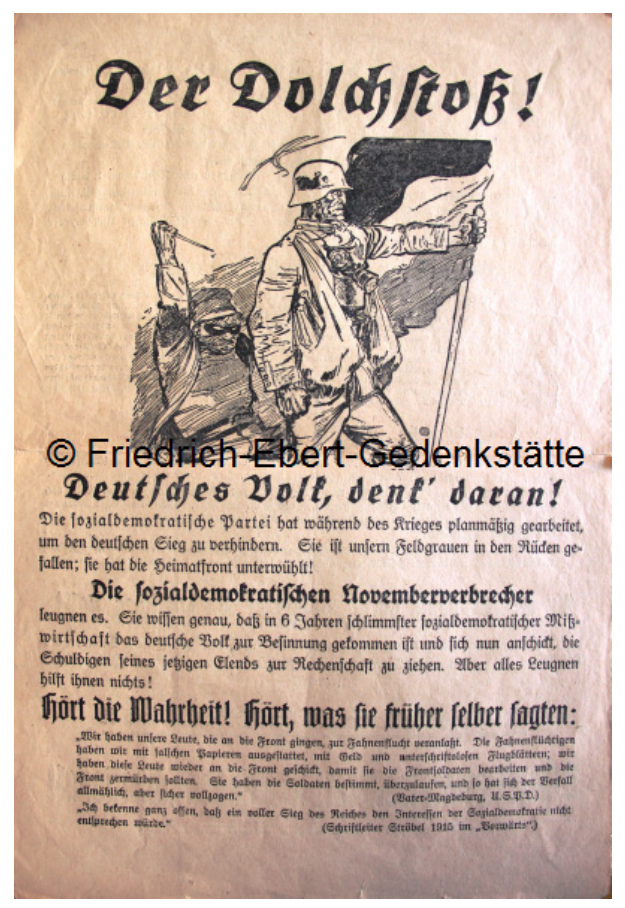

\section{Figura 4}

Fonte: Domínio público. Disponível em

http://www.ebert-gedenkstaette.de/dnvp_rtw_24_3.html

Também o líder do NSDAP desde 1921, Adolf Hitler, menciona a punhalada em seu livro Mein Kampf (publicada pela primeira vez em 1925), com a finalidade de culpabilizar os políticos que não teriam apoiado as tropas. Assim como no discurso de Hindenburg, no texto de Hitler, Siegfried apunhalado pelas costas representa à Pátria traída.

Wer damals nicht mitkämpfte, das waren die parlamentarischen Strauchdiebe, dieses gesamte politisierende Parteigesindel. Im Gegenteil, während wir in der Überzeugung kämpften, daß nur ein siegreicher Ausgang des Krieges allein auch dieses Südtirol dem deutschen Volkstum erhalten würde, haben die Mäuler dieser Ephialtesse gegen diesen Sieg so lange gehetzt und gewühlt, bis endlich der kämpfende Siegfried dem hinterhältigen Dolchstoß erlag. ${ }^{23}$ (Hitler, 1943, p. 707)

O poder de apelo no que diz respeito à imagem reiterada da punhalada contribuiu para a ascensão política de Hitler e para o gradual crescimento do NSDAP em território alemão. O que culmina, em 1933, na nomeação de Hitler como Reichskanzler (chanceler) pelo então presidente Hindenburg. Contudo, Seiler assevera que após este ano o vocábulo Legende (lenda) é retirado do sintagma por remeter ao significado de fantasia e/ou mentira, ficando apenas a menção à Dolchstoß (punhalada pelas costas) ou ainda Dolchstoßprozess (processo da punhalada pelas costas). A menção direta à palavra é, segundo o autor, suplantada pela utilização de imagens e de discursos que mencionam o processo em si sem nomeá-lo diretamente (Seiler, 1966, p. 18).

\footnotetext{
${ }_{23}$ "Quem, naquele momento, não lutou junto, estes foram os vagabundos parlamentares, toda essa corja politizada do partido. Pelo contrário, enquanto nós lutávamos acreditando que só a vitória poderia preservar Tirol do Sul para o povo alemão, as bocas de tais Ephialteses incitou e conspirou tanto tempo contra essa vitória até que, finalmente, o Siegfried lutador sucumbiu à punhalada traiçoeira nas costas."
} 
A partir de 1920 percebemos que as recepções de duas personagens da Nibelungenlied começam a ganhar espaço no cenário cultural da Alemanha republicana. Compreendemos recepção no sentido proposto por Köhn, ou seja, "nicht nur Wahrnehmung und Darstellung von Geschichte, sondern auch Auseinandersetzung und Aneignung oder Ablehnung, demnach jede Vermittlung und Vergegenwärtigung von Vergangenheit" ${ }^{24}$ (Köhn, 1991, p. 409). Neste contexto político, Siegfried e Hagen são, de forma controversa, as figuras escolhidas para ratificar novos discursos dentro de uma linha político-ideológica, pois como concluído por Helmut Brackert:

Die Geschichte der Rezeption des Nibelungenliedes ist nur erklärbar als der Reflex einer stetig zunehmenden Ideologisierung Deutschlands, dessen Verlauf nationale, dann nationalistische, dann imperialistische, schließlich rassisch-völkische Politiker bestimmten; der Nationalsozialismus bot nur eine letzte, allerdings unüberbietbare Form einer schon früh angelegten Perversion des Textes, der, solchermaßen verfälscht und simplifiziert, die ewige Gültigkeit längst abständiger, infantiler Tugendideale postulieren sollte und so für die gewissenlose Manipulation von politisch gefährlichen Interessen die ideelle Folie bereitstellte. ${ }^{25}$ (Brackert, 1991, p. 363).

Gradativamente essas menções as personagens Hagen e Siegfried, sejam em poemas, imagens ou discursos, vão crescendo e tomando forma, praticamente, de um culto aos dois guerreiros da Nibelungenlied.

No poema "Ein Lied Volkers" (1920), de Börries von Münchhausen, Hagen é celebrado como grande chefe militar (Mir dröhnt der Helm an den Ohren,/ Wenn Hagen im Kampf Befehle gibt), ${ }^{26}$ ainda que recaia sobre ele a morte de outro guerreiro, Siegfried, (Und ich sah doch beim Odenwald-Bronnen/ An seinem Speere auch Siegfrieds Blut!). ${ }^{27}$ Como forma de lee gitimação de seu herói, o eu-lírico argumenta ser testemunha ocular dos feitos do guerreiro e afirma que embora algumas manchas possam ser encontradas na armadura do comandante, isso não lhe retira o mérito de ser um grande soldado (Münkler, 2011, p. 89). Hagen, o herói medieval personifica, portanto, todo e qualquer bravo soldado que não foge a luta.

\section{(...) \\ Er ist, den die Edelsten scheuen, \\ Er ist von den Dornen des Grauens umzäunt, \\ Und der treueste aller Getreuen}

\footnotetext{
24 ."não somente (como) percepção e representação da história, mas também (como) discussão e apropriação ou rejeição, portanto, toda mediação e apresentação do passado"

25 "A história da recepção do Nibelungenlied é explicável apenas como o reflexo de uma ideologização cada vez maior da Alemanha, políticos nacionais, depois nacionalistas, então imperialistas, e finalmente racial-nacionalistas determinaram seu percurso. O nacional-socialismo ofereceu somente uma última, todavia, insuperável forma de uma, já anteriormente delineada, perversão textual, que de certa forma distorce e simplifica, que deveria postular a eterna validade de ideais de virtude há muito tempo ultrapassados e infatis e, assim, preparar o pano de fundo ideal para a manipulação inescrupulosa de interesses políticos perigosos."

26 "Em mim retumba o capacete nas orelhas,/ quando Hagen ordena em batalha"

${ }_{27}$ "E eu vi mesmo em Odenwald-Bronnen,/ em sua lança também o sangue de Siegfried"
} 
Fand selber nicht einen hingebenden Freund.

Wir gaben an klirrenden Tagen

Dem König den Schwertarm für billige Huld, -

Doch am schwersten Tage gab Hagen

An Gunther den Eid: »Mein Teil sei die Schuld!»

Drum, ob auch das Herz mir erzittert,

Als Siegfried gestöhnt und als Kriemhild geweint,

Doch bist du, vom Grauen umwittert,

Der Held meiner Lieder, mein Hagen, mein Freund!

(...)

Ele é, aquele que os mais nobres temem,

É cercado pelos espinhos do horror,

E o mais fiel de todos os companheiros

Não encontrou ele mesmo um amigo abnegado.

Nós demos em dias frios

Ao rei o punho da espada por graça barata -

Mas nos dias mais difíceis Hagen deu

A Gunther o juramento: "Minha parte seja a culpa!"

Em tempo, se também o coração me treme,

Quando Siegfried gemeu e quando Kriemhild chorou,

Mas és tu, de cinza envolto,

O herói das minhas canções, meu Hagen, meu amigo!

Entretanto, a personagem Hagen nem sempre é aclamada. Para Josef Weinheber, em seu poema "Siegfried-Hagen" (1936), Hagen personifica o inimigo interno. Desse modo, a personagem é despersonalizada e encarna "a ameaça interna do império". ${ }^{28}$ Em torno do herói é criada uma atmosfera de "falsidade, perfídia e traição" ${ }^{29}$ (Münkler, 2011, p. 88).

\section{(...)}

Wir schlugen uns selbst zu Stücken,

Ehrgier, Wurmgift, Neid.

Gegen den Speer im Rücken

Ist keiner gefeit.

Immer ersteht dem lichten

Siegfried ein Tronje im Nu.

\footnotetext{
28 "innere( ) Gefährdung des Reiches"

29 "Falschheit, Tücke udn Verrat"
} 
Weh, wie wir uns vernichten

Und das Reich dazu.

(...)

Nós abatemos a nós mesmos em pedaços,

Ambição, veneno de verme, inveja.

Contra a lança nas costas

Ninguém está imune.

Sempre renasce do iluminado

Siegfried um Tronje num piscar de olhos.

Infelizmente, como nós nos destruimos

$\mathrm{E}$, com isso, o reino.

Se para compreender a remitificação da personagem Hagen precisamos visualizar dois momentos distintos de sua recepção - um que valoriza seus feitos e outro que anexa à figura uma aura negativa de traidor da pátria -, as releituras referentes a Siegfried aparentemente são mais homogêneas e apontam para a personificação do herói sem máculas. Aparentemente, pois em 1923 na capa da revista Die Pleite é publicada uma caricatura de autoria de George Grosz nomeada Siegfried Hitler (figura 5). Grosz em sua obra desmitifica a figura de Siegfried ao associá-la a de Hitler. Embora a associação pudesse tomar um cunho mitificador para um público desavisado, a mídia na qual foi veiculada e a autoria não permitem tal associação: Die Pleite foi um jornal publicado de 1919 a 1924 e o foco principal era a crítica da cena sócio-cultural da República de Weimar e George Grosz, um de seus editores, entraria posteriormente para a lista dos artistas proibidos durante a ditadura nacional-socialista. Destacamos ainda o fato de que a imagem "was first printed after Hitler's abortive attempt to take over the Bavarian government in 1923, but it was reissued in 1930 when the Nazis had a more prominent profile in German politics"30 (West, 1988, p. 121-122).

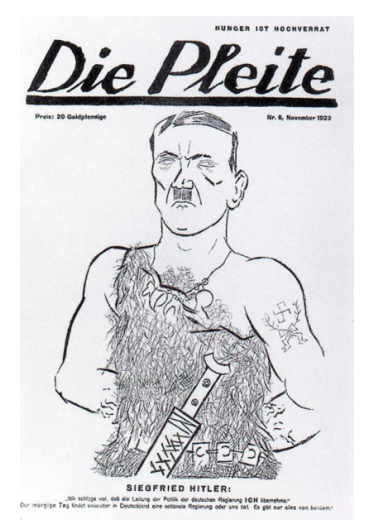

Figura 5

George Grosz, Siegfried Hitler, capa da revista Die Pleite de novembro 1923.

Fonte: Domínio público. Disponível em http://nlns.nl.ohost.de/lyrik5.4.htm

30 ."foi impressa pela primeira vez após a tentativa abortada de Hitler de tomar o governo da Bavária em 1923, mas foi reeditada em 1930 quando os nazistas tiveram um perfil mais prominente na política alemã” 
Contuto, a caricatura de Grosz destoa das demais recepções da personagem, que atribuem a Siegfried um caráter irrepreensível. Em sua obra Mein Kampf (1924), Hitler atribui a Siegfried o caráter de germanidade e iguala-o com a pátria: "Ein Feuer war entzündet, aus dessen Glut dereinst das Schwert kommen muß, das dem germanischen Siegfried die Freiheit, der deutschen Nation das Leben wiedergewinnen soll." ${ }^{31}$ (Hitler: 1943, p. 406). Também para Josef Weinheber ("Siegfried-Hagen", 1936), Siegfried incorpora a figura ariana de cabelos loiros e guerreira, que, todavia, não foi honrada pela pátria quando esta lhe virou as costas.

Held mit den blonden Haaren

Und mit dem schweren Schwert:

Wir waren, ach, wir waren

Deiner Tat nicht wert.

$(\ldots)$

Herói com os cabelos loiros

E com a espada pesada:

Nós não fomos, ai, nós não fomos

Dignos de seus feitos.

$(\ldots)$

Para o eu-lírico da "Das Lied von Siegfried" (Hans Henning von Grote, 1934), o inimigo é personificado através da imagem do dragão, que retorna ao território germânico, embora eliminado por Siegfried. Para acabar com um 'novo dragão' são necessárias lealdade, amor à pátria, união e que todos sejam heróicos como Siegfried: o alemão dos alemães. Notemos também o tom ufanista empregado pelo eu-lírico nos últimos versos.

\section{(...)}

Da floß in leuchtenden Fluten der deutsche Rhein -

Bis wieder einmal durch die Lande flammte der Warnungsschein:

Hört, Männer, gebt weiter in Eile die schlimme Kund',

Der alte Drache reckte sich wieder zur Stund',

W i r a ll e aber sind Retter!"

Denn wo endlich Männer ehern zusammenstehn,

Wo die heimischen Winde um Bruderstirnen wehn,

Wo ein großer Glaube in aller Herzen schlägt,

Wo nur die Heimatliebe ein Leben trägt,

Wo gegen finstere Mächte Mannentreue sich wehrt,

Wo aller Dinge Letztes das makellose Schwert,

Wo des Volkes Größe das erste Wort für die Welt:

Ersteht dem neuen Drachen wieder der neue Held,

\footnotetext{
31 "Um braseiro foi aceso, da sua chama ardente, um dia, virá a espada que restituirá ao Siegfried germânico a liberdade e à nação alemã, a vida."
} 
Siegfried, der Deutsche!

Lá corre em ondas brilhantes o Reno alemão -

Até que mais uma vez pelas terras arderam a nota de alerta:

Ouçam, homens, passem adiante apressadamente a terrível notícia,

$O$ velho dragão esticou-se novamente a esta hora,

Mas todos nós somos salvadores! “

Pois onde os homens finalmente estão juntos honrosamente,

Onde os ventos locais sopram ao redor das testas dos irmãos,

Onde uma grande fé pulsa em todos os corações,

Onde só o amor ao lar carrega uma vida,

Onde contra forças obscuras se volta a lealdade vassálica,

Onde todas as coisas por fim a espada imaculada,

Onde a grandeza do povo a primeira palavra para o mundo:

Renasce do novo dragão mais uma vez o novo herói,

Siegfried, o alemão!

Wilhelm von Scholz, em "Siegfriedsgesang" (1940), celebra Siegfried como o maior herói de todos os tempos, o guerreiro incansável, o bravo e forte Siegfried (Stark schleudert Siegfried den Stein). ${ }^{32}$ Por conseguinte, conclama outros guerreiros, provavelmente refere-se aos soldados, a erguer-se e lutar pela pátria como Siegfried destemidamente o fez.

\author{
(...) \\ Vielkämpfer: Ringer, und wäre sein Gegner der Bär! \\ Schleuderer, Läufer, Springer, Schwimmer - \\ Der Sieger, der Beste, immer, immer, \\ immer nur er! \\ Siegfried! \\ Auf, Kämpfer, ihm nach! \\ Auf zu des Wettstreits Schönheit und Kraft \\ Die Muskeln gestrafft! \\ Den Blick gehärtet! \\ Das Herz gestählt! \\ Daß auch unsere Namen \\ wie Siegfrieds Namen \\ Dichtermund der Nachwelt erzählt! \\ Zum Kampf!
}

(...)

Multi guerreiro: lutador, e se seu adversário fosse o urso!

\footnotetext{
32 "forte Siegfried arremessa a pedra". Provável referência ao embate com Brünhild, no qual Siegfried encontra-se invisível e executa as tarefas por Gunther (cf. 7. Aventiure - Wie Gunther Prünhilde gewan)
} 
Arremessador, corredor, saltador, nadador -

O vencedor, o melhor, sempre, sempre,

Sempre só ele!

Siegfried!

De pé, guerreiros, sigam-no!

De pé para o concurso de beleza e poder

Os músculos esticados!

A visão endurecida!

O coração acerado!

Que também os nossos nomes

como o nome de Siegfried

narrado pela boca do poeta da posteridade!

A luta!

\section{CASO 4: DIE NIBELUNGEN ${ }^{33}$}

Se no terceiro caso aqui analisado, Hagen e Siegfried parecem não ocupar o mesmo espaço, o quarto caso aqui destacado como proposta de análise apresenta aquelas remitificações que unem as duas personagens para falar da bravura do povo nibelungo.

Envolto em um saudosismo, o eu-lírico do poema Nibelungenland (de Max Braun, 1933) encontra-se em um castelo e sonha com os grandes heróis do passado: Siegfried, o forte e Hagen, o obstinado. Como em oração solicita que esses espíritos heróicos guiem o caminho daqueles que partem em marcha para a guerra. O tom nacional-socialista fica confirmado pela saudação inserida no poema: Heil! Os nibelungos representam, neste poema, todos os alemães que partiram para a guerra.

Es war das Nibelungenland

Von den Zinnen dieses Schlosses

Blicke sinnend ich zu Tale:

Alte Zeiten steigen träumend.

Ringsum grüßen Heldenmale.

Siegfried stark und Hagen trutzig,

Eures Hüfthorns Klänge fehlen!

Geist von eurem Geiste möge

Uns in dieser Stund beseelen!

Durch den Wald seh ich euch schreiten.

Heil! Ich grüß euch tapfere Mannen!

33 Os Nibelungos. 
Siegfrieds Spuren folg ich sinnend:

Siegfrieds Horn schallt durch die Tannen.

Nun zum letzten Sammeln blaset,

Helden, die dereinst gerungen!

Letzten Kampf gilt es zu kämpfen,

Kampf der letzten Nibelungen!

Era a terra dos Nibelungos

Do merlão do castelo

Eu olho pensativo para o vale:

Velhos tempos sobem em sonho.

Ao redor, saúdam heróis.

Siegfried forte e Hagen obstinado,

Os sons de seus cornos faltam!

Espírito de seus espíritos

Anime-nos nesta hora!

Pela floresta eu vejo vocês marcharem.

Heil! Saúdo-vos, homens bravos!

Os passos de Siegfried sigo pensativo:

O Chifre de Siegfried ecoa pelos pinheiros.

Agora, soprem para o último encontro,

Heróis, que lutaram um dia!

Última luta vale para combatê-la,

Batalha dos últimos Nibelungos!

Dentro dessa lógica que substitui alemães por nibelungos, Hermann Göring, discure sa em trinta de janeiro de 1943 no Ehrensaal des Reichsluftfahrtministeriums, convocando todos os militares a se unir em um só esforço, com suas vidas, com seu sangue, para que a batalha de Stalingrado pudesse ser vencida. Essa batalha é, assim, relida como sendo a grande batalha dos nibelungos.

Und aus all diesen gigantischen Kämpfen ragt nun gleich einem gewaltigen, monumentalen Bau Stalingrad, der Kampf um Stalingrad heraus. Es wird dies einmal der größte Heroenkampf gewesen sein, der sich jemals in unserer Geschichte abgespielt hat. [...] - wir kennen ein gewaltiges, heroisches Lied von einem Kampf ohnegleichen, das hieß "Der Kampf der Nibelungen“. Auch sie standen in einer Halle von Feuer und Brand und löschten den Durst mit eigenem Blut - aber kämpften und kämpften bis zum letzten. Ein solcher Kampf tobt heute dort, und jeder Deutsche 
noch in tausend Jahren muß mit heiligen Schaudern das Wort Stalingrad aussprechen und sich erinnern, daß dort Deutschlands letzten Endes doch den Stempel zum Endsieg gesetzt hat. ${ }^{34}$ (Göring, 1943)

Mais uma tentativa militar de insuflar as forças militares a reagir as perdas é a fundação da 38 a Divisão de Infantaria Motorizada da Waffen-SS, batizada de Nibelungen. A última a ser formada, em março de 1945, traz como emblema (figura 6) o elmo nibelungo próprio das representações dos dramas musicais wagnerianos.

SS-Panzergrenadierdivision Nibelungen: Formada, por ordem de Hitler, para defesa no Oeste, com recrutas abaixo da idade de conscrição, além de cadetes e quadros oriundos da Academia Militar das Waffen-SS em Bad Tolz. Travou combates acirrados na Alta Bavária e Landshut. Capitulou para os americanos nos Alpes. (Keegan, 1973, p.155)

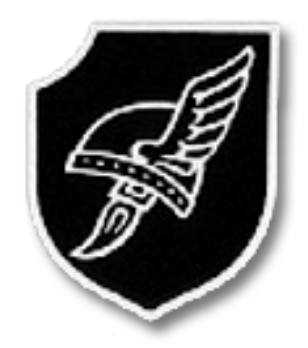

\section{Figura 6}

Emblema da 38a Divisão de Infantaria Motorizada da Waffen-SS

Domínio público. Disponível em http://commons.wikimedia.org/wiki/File:38divss.gif

Destarte, concluimos que os discursos em torno da matéria nibelunga criaram uma máquina política efetiva que se afirmou nas remitificações politizando-as e utilizando-as dentro de lógicas e mecanismos de poder para legitimar a dominação de um determinado discurso sobre outro. Hans Naumann em 1942 (Das Nibelungenlied - eine staufische Elegie oder ein deutsches Nationalepos?) chega ao ponto de elevar a Nibelungenlied ao status de Nationalepos. As análises aqui proo postas das releituras da Nibelungentreue, da Dolchstoßlegende, das personagens Siefried e Hagen e dos Nibelungen permitem, portanto, visualizar que deslocadas de seu significado originário tais temas foram resimbolizados servindo a um discurso político que pretendia se afirmar em cima de outros vigentes. A remitificação do mito à nível político revela toda a força geracional que esse tem, ou seja, o poder de criar novas lógicas, novos arranjos sociais.

\footnotetext{
34 "E de todas essas batalhas gigantescas sobressai agora uma enorme, monumental construção em Stalingrado, a Batalha em torno de Stalingrado. Essa deve ser uma vez a maior batalha heróica que já se deu em nossa história. [...] - conhecemos uma enorme canção heróica sobre uma batalha sem igual, que se chamava "A batalha dos Nibelungos". Também eles encontravam-se em um salão de fogo e incêndio e extinguiram a sede com o seu próprio sangue - mas lutaram e lutaram até o fim. Uma tal batalha castiga hoje lá, e todos os alemães ainda devem pronunciar em mil anos com santo horror a palavra Stalingrado e lembrar-se de que lá a Alemanha, finalmente, estampou o selo da vitória final.”
} 


\section{REFERÊNCIAS}

BAUMAN, Zygmunt. Ensaios sobre o conceito de cultura. Tradução de Carlos Alberto Medeiros. Rio de Janeiro: Jorge Zahar, 2012.

BRACKERT, Helmut. Nibelungenlied und Nationalgedanke. Zur Geschichte einer deutschen Ideologie. In: HENNIG, Ursula/ KOLB, Herbert (org.): Mediævalia litteraria. Festschrift für Helmut de Boor zum 80. Geburtstag. München: C. H. Beck'sche Verlagsbuchhandlung, 1971, p. 343-364.

BRANDT, Rüdiger. Grundkurs germanistische Mediävistik, Literaturwissenschaft. München: Wilhelm Fink, 1999.

EHRISMANN, Otfrid. Ehre und Mut, Aventiure und Minne. Höfische Wortgeschichten aus dem Mittelalter. München: C. H. Beck, 1995.

ELIADE, Mircea. Mito e realidade. Tradução de Pola Civelli. São Paulo: Perspectiva. 1998.

GÖRING, Hermann. Rede im Ehrensaal des Reichsluftfahrtministeriums. 30 janeiro de 1943. Disponível em http://www.univie.ac.at/hypertextcreator/europa/site/browse. php?artiid=1106\&arttyp=k Acessado em 15/12/2013.

GROTE, Hans Henning von. Das Lied von Siegfried. In: Deutsche Heldendichtung. Ein Jahrtausend deutscher Geschichte in Liedern. Ausgewählt und eingeleitet von Mirko Jelusich. Leipzig: Das neue Deutschland o. J., 1934, p. 55-57.

HEINZLE, Joachim (org.). Mythos Nibelungen. Stuttgart: Reclam, 2013.

HINDENBURG, Paul von. Aus meinem Leben. Hamburg: Severus, 2013.

HITLER, Adolf. Mein Kampf. München: Eher-Verlag, 1943.

KAISER, Gerhard. Literarische Romantik. Göttingen: Vandenhoeck \& Ruprecht, 2010.

KEEGAN, John. Waffen-SS - Os Soldados da Morte. Tradução de Edmond Jorge. Rio de Janeiro: Ed. Renes, 1973.

KÖHN, Rolf. Was ist und soll eine Geschichte der Mittelalterrezeption? Thesen eines Historikers. In: BURG, Irene et alii. (org.) Mittelalter-Rezeption IV: Medien, Politik, Ideologie, Ökonomie. Göppingen: Kümmerle Verlag, 1991, p. 407-431.

LAUBE, Stefan. Nationale Identität und Erinnerung. Von imaginären Spuren zur kulturellen Einheit. Disponível em http://www.stefanlaube.homepage.t-online.de/NationErinnerung.pdf Acessado em $13 / 11 / 2012$. 
MIGUEL, Luis Felipe. Em Torno do Conceito de Mito Político. In: Dados, v. 41, n. 3, 1998. Disponível em http://www.scielo.br/scielo.php?script=sci_arttext\&pid=S0011-52581998000300005\&lng=en\&nrm =iso Acessado em 14/12/2013.

MIKLAUTSCH, Lydia. „Was gehen die Nibelungen an?“ (Einar Schleef) zur Rezeption und Wirkungsgeschichte des Nibelungenliedes. In: Línguas e Literaturas: Revista da Faculda de Letras, Porto, XI, pp. 369-378, 1994.

MÜNCHHAUSEN, Börries von. Ein Lied Volkers. In: . Das dichterische Werk in zwei

Bänden. vl. 1 - Das Balladenbuch. Stuttgart: Deutsche Verlagsanstalt, 1951, p. 64-65.

MÜNKLER, Herfried. Die Deutschen und ihre Mythen. Berlin: Rowohlt, 2011.

SAFRANSKI, Rüdiger. Romantik: eine deutsche Affäre. Frankfurt am Main: Fischer, 2009.

SCHOLZ, Wilhelm von. Siegfriedsgesang. In: Die Gedichte. Gesamtausgabe. Leipzig: Paul List, 1944, p. 432f.

SCHULZE, Hagen. Staat und Nation in der europäischen Geschichte. München: C. H. Beck, 2004.

SEILER, Bernd. Dolchstoß und Dolchstoßlegende. In: Zeitschrift für deutsche Sprache 22, pp.1-20, 1966.

WEST, Shearer. The Visual Arts in Germany 1890-1937: Utopia and Despair. Manchester: Machester Unviersity Press, 1988. 